\title{
Identification of cancer risk and associated behaviour: implications for social marketing campaigns for cancer prevention
}

Rebecca Kippen ${ }^{1 *} \mathbb{D}$, Erica James ${ }^{2}$, Bernadette Ward ${ }^{1}$, Penny Buykx ${ }^{3}$, Ardel Shamsullahn ${ }^{1}$, Wendy Watson ${ }^{4}$ and Kathy Chapman ${ }^{4}$

\begin{abstract}
Background: Community misconception of what causes cancer is an important consideration when devising communication strategies around cancer prevention, while those initiating social marketing campaigns must decide whether to target the general population or to tailor messages for different audiences. This paper investigates the relationships between demographic characteristics, identification of selected cancer risk factors, and associated protective behaviours, to inform audience segmentation for cancer prevention social marketing.

Methods: Data for this cross-sectional study $(n=3301)$ are derived from Cancer Council New South Wales' 2013 Cancer Prevention Survey. Descriptive statistics and logistic regression models were used to investigate the relationship between respondent demographic characteristics and identification of each of seven cancer risk factors; demographic characteristics and practice of the seven 'protective' behaviours associated with the seven cancer risk factors; and identification of cancer risk factors and practising the associated protective behaviours, controlling for demographic characteristics.

Results: More than $90 \%$ of respondents across demographic groups identified sun exposure and smoking cigarettes as moderate or large cancer risk factors. Around $80 \%$ identified passive smoking as a moderate/large risk factor, and 40-60\% identified being overweight or obese, drinking alcohol, not eating enough vegetables and not eating enough fruit. Women and older respondents were more likely to identify most cancer risk factors as moderate/large, and to practise associated protective behaviours. Education was correlated with identification of smoking as a moderate/large cancer risk factor, and with four of the seven protective behaviours. Location (metropolitan/regional) and country of birth (Australia/other) were weak predictors of identification and of protective behaviours. Identification of a cancer risk factor as moderate/large was a significant predictor for five out of seven associated cancer-protective behaviours, controlling for demographic characteristics.

Conclusions: These findings suggest a role for both audience segmentation and whole-of-population approaches in cancer-prevention social marketing campaigns. Targeted campaigns can address beliefs of younger people and men about cancer risk factors. Traditional population campaigns can enhance awareness of being overweight, alcohol consumption, and poor vegetable and fruit intake as cancer risk factors.
\end{abstract}

Keywords: Cancer, Social marketing, Risk factors

\footnotetext{
* Correspondence: rebecca.kippen@monash.edu

${ }^{1}$ School of Rural Health, Monash University, PO Box 666, Bendigo, VIC 3552,

Australia

Full list of author information is available at the end of the article
} 


\section{Background}

In Australia, around one-third of cancer cases are due to six modifiable lifestyle risks: tobacco use, ultraviolet radiation exposure, inadequate diet, overweight and obesity, alcohol consumption, and lack of physical activity [1]. This reflects international research that finds globally, around one-third of cancer deaths are due to smoking, low fruit and vegetable intake, overweight and obesity, alcohol consumption, and physical inactivity [2].

One obstacle that challenges cancer prevention is the existing community scepticism that cancer can be prevented, [3] despite research indicating that only $5 \%$ of cancers are hereditary $[3,4]$. There is currently poor community understanding of what causes cancer and how to reduce risk $[5,6]$. In an Australian study examining cancer patient beliefs surrounding the development of cancer, almost half of respondents did not know what factors contributed to their cancer, whilst few participants identified behavioural risks as causal factors [5]. Similarly, in a study investigating the beliefs and perceptions held by women regarding the causes of breast cancer, results indicated that while most respondents nominated factors that they believed contribute to the development of breast cancer, a large number of these factors are not supported by scientific evidence. The authors conclude that such misunderstandings of the causes of cancer could negatively affect the efficacy of campaigns for cancer prevention [6].

Compared to tobacco and sun exposure, there is much lower recognition of the carcinogenic effects of the other main established lifestyle causes of cancer, especially obesity, physical inactivity and alcohol [7-9]. Sun exposure and diet show significant recognition in some national surveys but not in others. One UK study that examined public awareness of the associations with lifestyle of both cancer and heart disease found that awareness was significantly higher for the latter, with the authors noting that the link between lifestyle factors and cancer (bar lung cancer) has been publicised only recently [7]. In Australia, results from a series of surveys largely parallel international findings, indicating high awareness of the links between smoking and lung cancer (96\%) and sun exposure and melanoma (80\%), but much lower, although marginally improving, awareness of other health-behaviour cancer risk factors [8]. The 2000 survey in this series found that fewer than $40 \%$ of people believed that they could 'greatly reduce' their personal risk of cancer. Awareness of lifestyle factors associated with cancer were lower than for other common diseases [8]. Knowledge of the cancer risks of too much alcohol increased from $41 \%$ in 2006 to $48 \%$ in 2009, however remained well below awareness that excessive drinking could result in liver problems $(98 \%)$ or being overweight or obese $(89 \%)$ [9].
Community perceptions of avoidable cancer risk factors are a vital consideration in the development of communication strategies for cancer prevention [5]. Public awareness of cancer risk is of significant importance if messages about changing behaviour and engaging in screening are to be seen as relevant by target groups. Whilst it is unrealistic to expect that public health campaigns could utterly transform entrenched unhealthy lifestyles, they can make a difference when their messages reach and are absorbed by the public. Even modest improvements in health behaviours, given the scale of the problem of unhealthy lifestyles, can make a substantial improvement to population mortality and morbidity. International studies of public awareness of cancer risks consistently show that the primary problem is that many people have only patchy appreciation of the gravity of cancer risks associated with what may seem 'normal' lifestyles [6-8]. Multicomponent, comprehensive health promotion is most likely to effectively influence behaviour change [10] and this may include social marketing campaigns.

Social marketing applies commercial marketing strategies to modify social behaviours for the benefit of the community, including those behaviours related to public health [11]. Methods are "drawn from behavioural theory, persuasion psychology, and marketing science with regard to health behaviour, human reactions to messages and message delivery, and the 'marketing mix' or 'four Ps' of marketing (place, price, product, and promotion)" [11, 12]. As a discipline, modern social marketing has started to incorporate the powerful tool set utilised by commercial marketing professionals, such as analysing specific audiences and targeting them with customised messages [11]. Using mediums such as print media, television, radio, digital media and billboards, health-related social marketing campaigns are implemented with intent of effecting voluntary change in the health behaviours of large populations, often in part through provoking cognitive or emotional responses within audiences as a result $[13,14]$.

Those initiating social marketing campaigns must decide whether to target the general population or to tailor messages for different audiences with differing demographic, cultural, or behavioural characteristics [11]. Audience segmentation for cancer prevention may be particularly important since there are geographical and social differences in cancer awareness and related health outcomes. Social marketing therefore requires analysis of the relationship between demographic characteristics, current knowledge of cancer risk factors and current behaviours. This paper aims to investigate the relationship between respondent demographic characteristics and identification of seven cancer risk factors, and to determine whether respondents who identified a particular cancer risk factor as 'Moderate/large' were more likely to practise the recommended behaviour. 


\section{Methods}

Data for this study are from the Cancer Prevention Survey carried out in 2013 by Cancer Council New South Wales (NSW) [see Additional file 1]. There were 3301 respondents to the 20-min survey, all of whom were adult residents of NSW. Each respondent was randomised to three of four cancer-prevention topics: sun protection ( $n=2474$ respondents), tobacco control $(n=2473)$, nutrition $(n=2474)$ and alcohol $(n=2482)$ [15].

The sample was recruited by a market research company from their participant database. An invitation to respond to an online survey on personal health was emailed to 30,179 adults living in NSW. Of these, 5290 began the screening questions. A total of 962 people were screened out because quota limits for respondent age, sex, location and education had been reached $(n=760)$, because they were undergoing treatment for cancer $(n=123)$, or because they worked in the advertising industry or in the manufacture or sale of alcohol or tobacco products $(n=79)$. Another 983 began the survey but did not complete it, and 44 responses were omitted because they were completed in less than onethird of the median survey time or showed minimal variability across scale items [15].

\section{Demographic characteristics}

Demographic characteristics of respondents included in this study were sex (male/female), age (18-29 years, 30-49 years, 50 years and over), residential location (metro/regional), education (up to year 10, year 11 or 12, diploma/certificate, university degree) and country of birth (Australia/other). These questions were answered by all 3301 respondents. Responses were weighted in the reported analyses so that the sample reflected the distribution of the NSW adult population by sex, age, location and education [15].

\section{Identification of cancer risk factors}

Respondent identification of cancer risk factors was captured through the question 'How much do each of the following things contribute to a person's risk of getting cancer?', with scale responses 'None,' 'Slight,' 'Moderate' and 'Large', and an alternative option of 'Don't know'.

The list of cancer risk factors included the following seven behavioural items (see also Table 1):

1. Spending time outdoors during peak ultraviolet radiation (UV) times without sun protection

2. Smoking cigarettes

3. Passive smoking

4. Being overweight or obese

5. Drinking alcohol

6. Not eating enough vegetables

7. Not eating enough fruit

\section{Behaviour}

Each of these seven risk factors was matched with an associated behaviour, self-reported by the respondent in the survey, and coded as either a 'protective' or 'risk' behaviour. These are outlined below (see also Table 1).

\section{Risk factor: spending time outdoors during peak UV times without sun protection}

Risk behaviour: Tried to get a tan from the sun or used a solarium this summer

This behaviour was measured by responses to two questions: 'Which of the following things have you done this summer?'-'Used a solarium'; and 'Which of the following things have you done this summer?'-'Tried to get a tan from the sun'. The survey was carried out at the end of the Australian summer in February 2013. Possible response categories were 'Yes', 'No' and 'Don't

Table 1 Seven cancer risk factors and associated risk and protective behaviours

\begin{tabular}{|c|c|c|}
\hline Cancer risk factor & Risk behaviour & Protective behaviour \\
\hline $\begin{array}{l}\text { 1. Spending time outdoors during } \\
\text { peak UV times without sun protection }\end{array}$ & $\begin{array}{l}\text { 1. Tried to get a tan from the sun } \\
\text { or used a solarium this summer }\end{array}$ & $\begin{array}{l}\text { 1. Sunsafe: Did not try to get a } \\
\text { tan from the sun nor used a } \\
\text { solarium this summer }\end{array}$ \\
\hline 2. Smoking cigarettes & $\begin{array}{l}\text { 2. Daily or occasional smoker } \\
\text { of cigarettes, cigars or pipes }\end{array}$ & $\begin{array}{l}\text { 2. Non-smoker: Does not smoke } \\
\text { cigarettes, cigars nor pipes }\end{array}$ \\
\hline 3. Passive smoking & $\begin{array}{l}\text { 3. Does not try to avoid places } \\
\text { where s/he may be exposed to } \\
\text { other people's cigarette smoke }\end{array}$ & $\begin{array}{l}\text { 3. Avoid passive smoke: Tries to } \\
\text { avoid places where s/he may be } \\
\text { exposed to other people's cigarette } \\
\text { smoke }\end{array}$ \\
\hline 4. Being overweight or obese & 4. Body Mass Index (BMI) of 25 or more & $\begin{array}{l}\text { 4. Healthy weight: BMl of } 18.5 \\
\text { to less than } 25.0\end{array}$ \\
\hline 5. Drinking alcohol & $\begin{array}{l}\text { 5. AUDIT-C score of } 4 \text { or more } \\
\text { for men and } 3 \text { or more for women }\end{array}$ & $\begin{array}{l}\text { 5. Lower risk alcohol intake: AUDIT-C } \\
\text { score of 0-3 for men and 0-2 for } \\
\text { women }\end{array}$ \\
\hline 6. Not eating enough vegetables & $\begin{array}{l}\text { 6. Eating fewer than five serves } \\
\text { of vegetables per day }\end{array}$ & $\begin{array}{l}\text { 6. 5+ vegetable serves: Eating five or } \\
\text { more serves of vegetables per day }\end{array}$ \\
\hline 7. Not eating enough fruit & $\begin{array}{l}\text { 7. Eating fewer than two serves of } \\
\text { fruit per day }\end{array}$ & $\begin{array}{l}\text { 7. } 2+\text { fruit serves: Eating two or more } \\
\text { serves of fruit per day }\end{array}$ \\
\hline
\end{tabular}


know'. Of the 2474 participants who answered these questions, $1973(79.7 \%)$ stated 'No' to both, while 501 (20.3\%) said 'Yes' or 'Don't know' to one or both questions. 'Don't know' constituted $0.7 \%$ of responses to 'Tried to get a tan from the sun' and $1.1 \%$ of responses to 'Used a solarium'. Those who responded 'No' to both questions were coded as exhibiting protective 'Sunsafe behaviour' while the other 501 respondents were coded as 'Sun vulnerable behaviour'.

\section{Risk factor: smoking cigarettes}

Risk behaviour: Daily or occasional smoker of cigarettes, cigars or pipes

All survey participants were asked 'Which of the following best describes your smoking status? This includes cigarettes, cigars and pipes.' with possible responses 'I smoke daily,' 'I smoke occasionally,' 'I don't smoke now, but I used to,' 'I've tried it a few times, but never smoked regularly', and 'I've never smoked'. The first two of these responses were coded as 'Smoker' $(n=567,17.2 \%)$ with the last three coded as 'Non-smoker' $(n=2734,82.8 \%)$.

\section{Risk factor: passive smoking}

Risk behaviour: Does not try to avoid places where s/he may be exposed to other people's cigarette smoke

This behaviour was coded from 2473 responses to the statement 'I try to avoid places where I may be exposed to other people's cigarette smoke'. 'Agree' and 'Strongly agree' were coded as 'Avoids passive smoke' ( $n=1681$, $68.0 \%)$ while 'Disagree, 'Strongly disagree, 'Neither' and 'Don't know' were coded as 'Does not avoid passive smoke' $(n=792,32.0 \%)$.

\section{Risk factor: being overweight or obese}

Risk indicator: Body Mass Index (BMI) of 25 or more

Height and weight were asked of all 3301 survey participants but reported by only 2790 respondents. BMI, equal to [weight in kilograms] /[(height in metres) $\left.{ }^{2}\right]$, was calculated for these respondents. Fifty respondents (1.8\%) with BMIs of less than 18.5 ('Underweight') were excluded from analysis. Respondents with BMIs of 18.5 to less than 25.0 were coded as 'Healthy weight' $(n=1087,39.0 \%)$. Respondents with BMIs of 25.0 or greater were coded as 'Overweight' ( $n=1653,59.2 \%)$. These BMI ranges for 'Underweight', 'Healthy weight' and 'Overweight' follow Australian Healthy Weight guidelines [16].

\section{Risk factor: drinking alcohol}

Risk behaviour: AUDIT-C score of four or more for men and three or more for women

The AUDIT-C (Alcohol Use Disorders-Identification Test-Consumption) score measures alcohol consumption on a scale from 0 to 12 and is designed to detect heavy drinking or alcohol abuse [17]. Questions on personal alcohol consumption were asked of the 2482 survey participants randomised to the cancer-prevention topic around alcohol, and answered by 2462 respondents, allowing calculation of individual AUDIT-C scores. Following Rubinsky et al., [18] scores of 4 or more for men and 3 or more for women were coded as 'Higher-risk alcohol intake' $(n=1361,55.3 \%)$. Scores of $0-3$ for men and $0-2$ for women were coded as 'Lower-risk alcohol intake' $(n=1101,44.7 \%)$.

\section{Risk factor: not eating enough vegetables}

Risk behaviour: Eating fewer than five serves of vegetables per day

There were 2474 answers to the question 'If a serve of vegetables is equal to half a cup of cooked vegetables, one medium potato or one cup of salad, how many SERVES of vegetables do you eat each day, on average?' with responses coded as ' 5 or more vegetable serves' $(n=255,10.3 \%)$ and 'Less than 5 vegetable serves' ( $n=2219,89.7 \%)$. This follows Australian government guidelines for recommended daily vegetable intake [19].

\section{Risk factor: not eating enough fruit}

Risk behaviour: Eating fewer than two serves of fruit per day

This behaviour was coded from responses to 'If a serve of fruit is equal to one medium piece or two small pieces of fruit, or one cup of diced fruit, how many SERVES of fruit do you eat each day, on average?'. Of 2474 respondents, $1417(57.3 \%)$ were coded as '2 or more fruit serves' and 1057 (42.7\%) were coded as 'Less than 2 fruit serves'. This follows Australian government guidelines for recommended daily fruit intake [19].

\section{Analysis}

Seven logistic regressions were conducted to investigate the relationship between respondent demographic characteristics and identification of each of the seven cancer risk factors as either 'Moderate/large' or 'None/slight' (with 'Don't know' responses excluded). A second set of logistic regressions was conducted to examine the relationship between respondent demographic characteristics and the seven 'protective' behaviours outlined in the previous section. Finally, a third set of regressions were conducted to determine whether respondents who identified a particular cancer risk factor as 'Moderate/ large' were more likely to practise the associated 'protective' behaviour than were respondents who identified the risk factor as 'None/slight', controlling for demographic characteristics.

\section{Results}

Figures 1, 2, 3, 4, 5, 6, 7 show percentage distributions of respondent identification of each of the seven cancer 

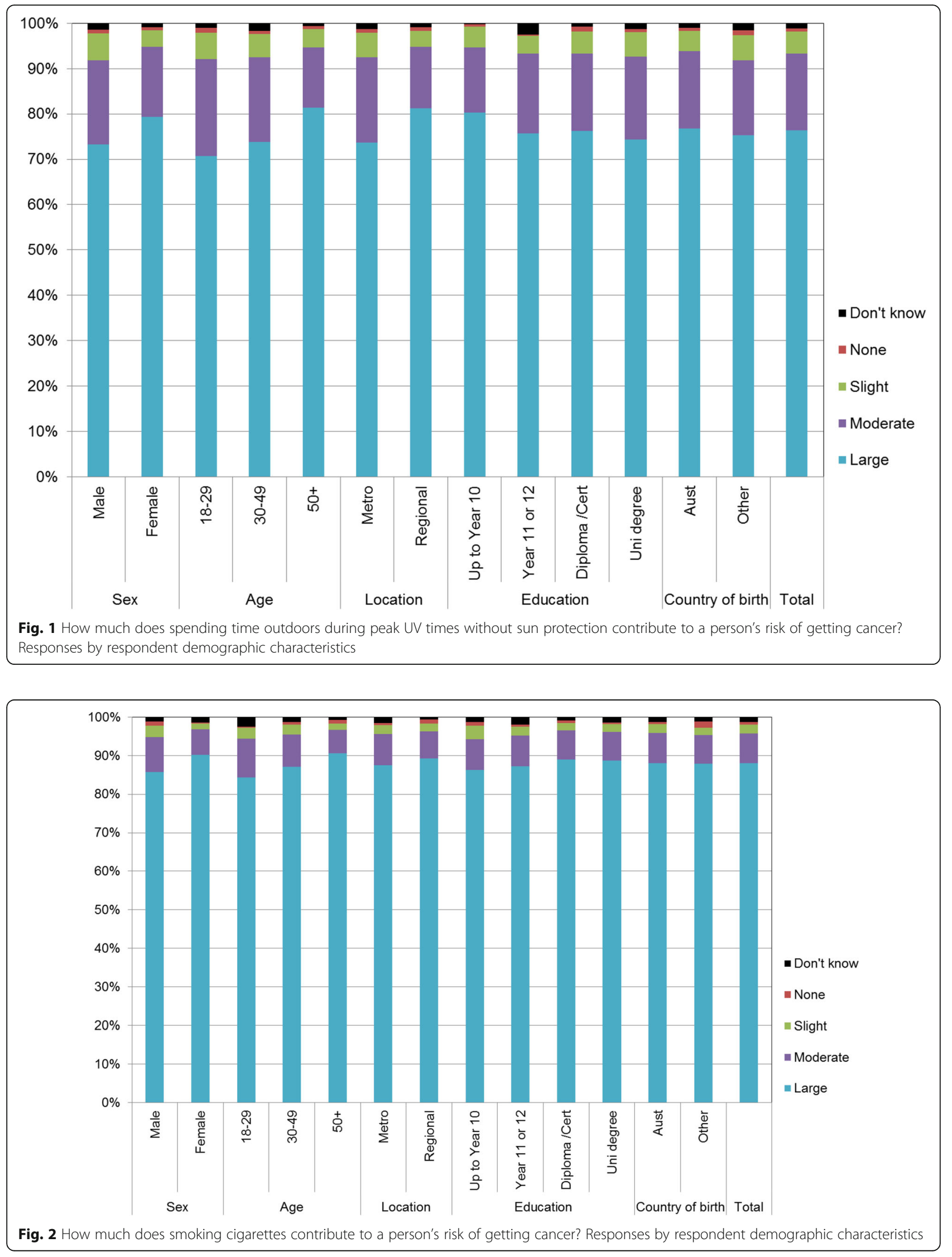

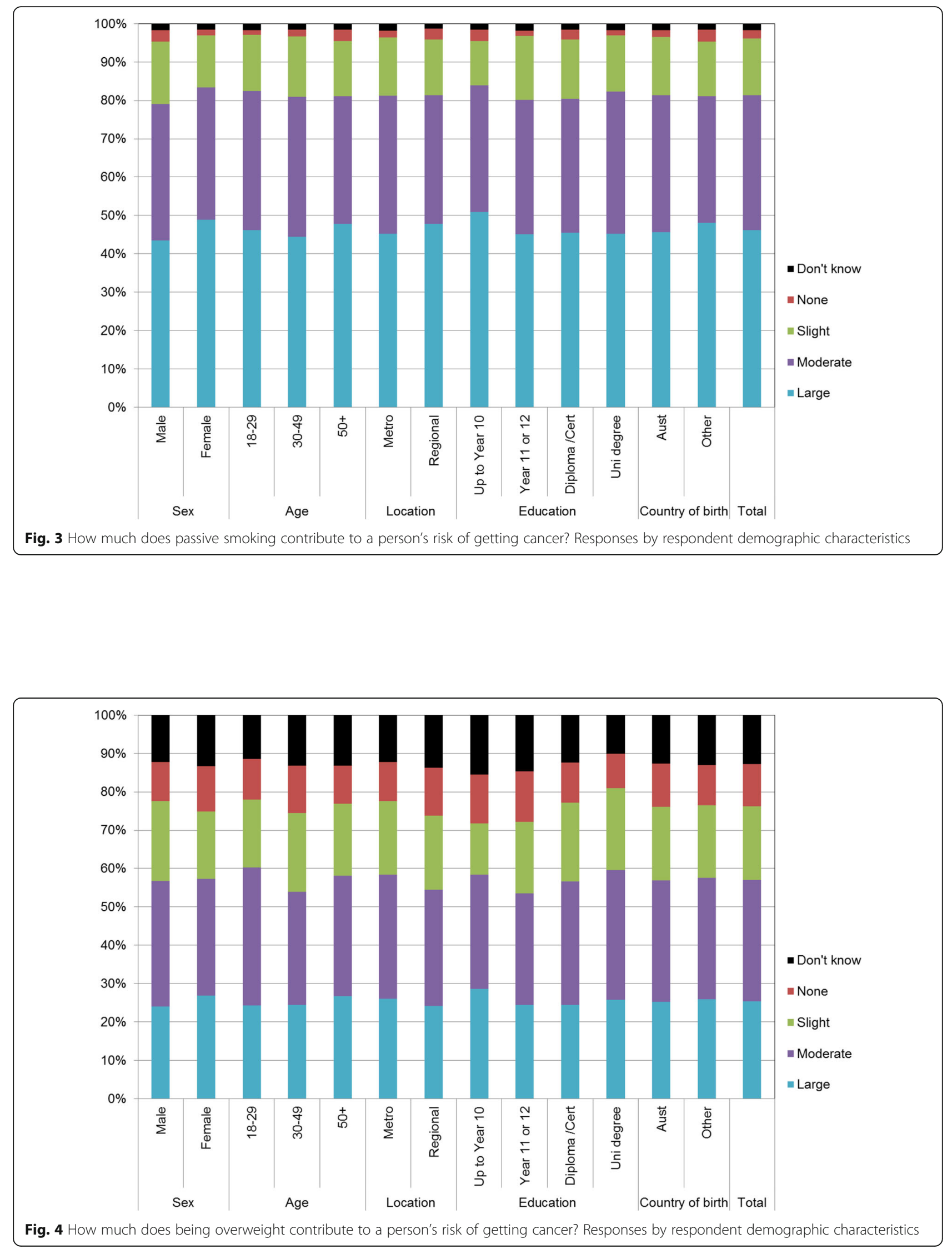

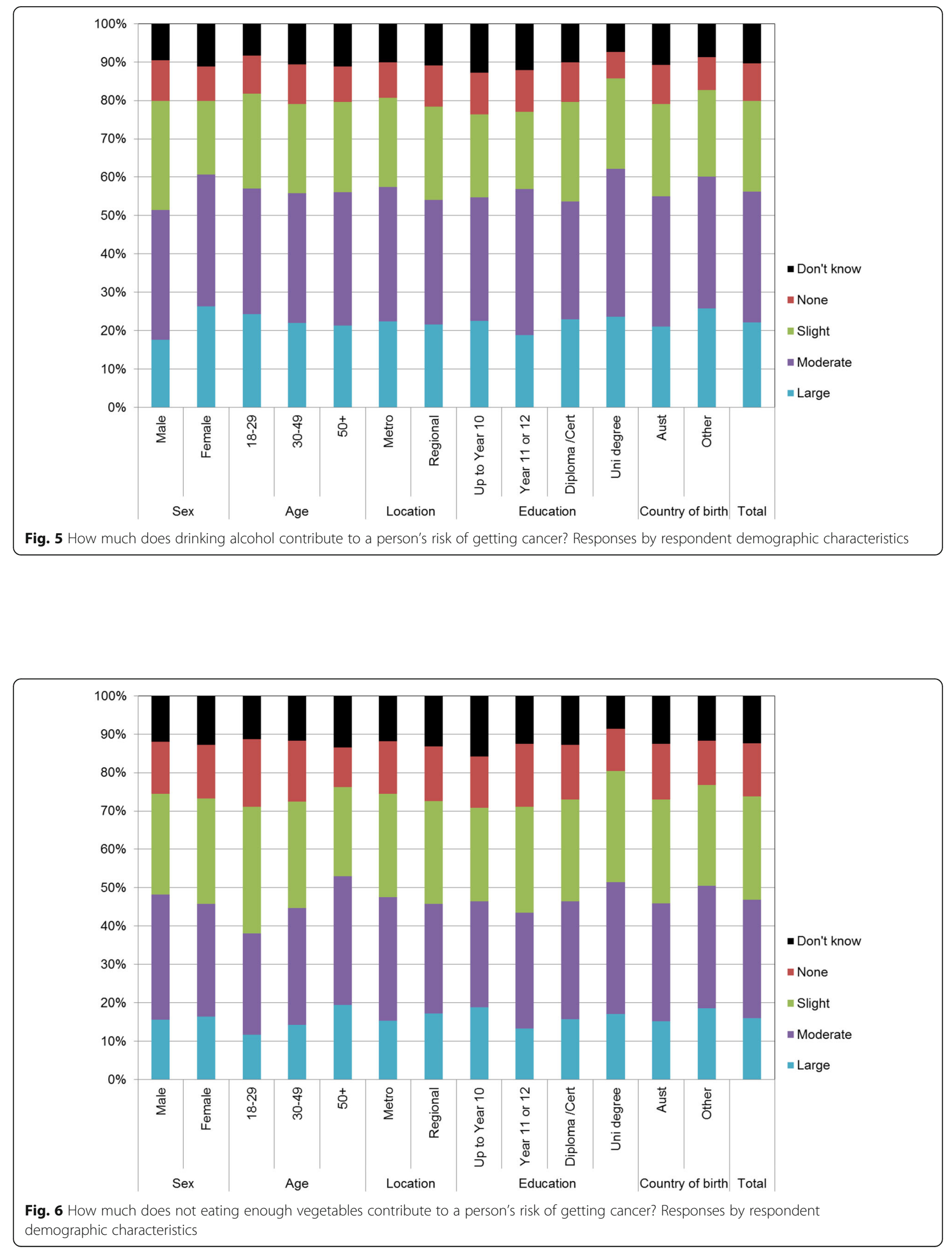


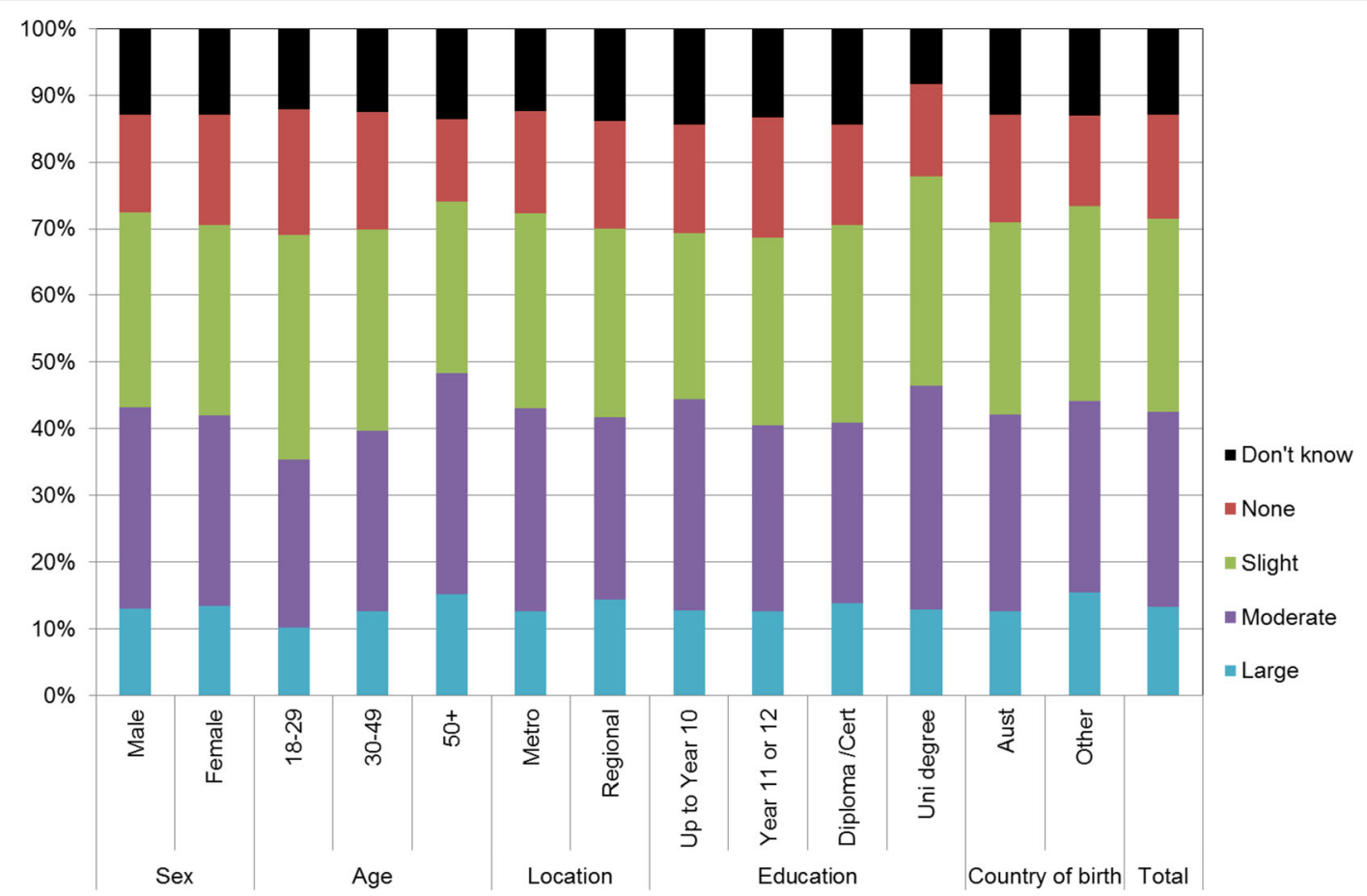

Fig. 7 How much does not eating enough fruit contribute to a person's risk of getting cancer? Responses by respondent demographic characteristics

risk factors as 'Large,' 'Moderate,' 'Slight,' 'None' or 'Don't know' by respondent demographic characteristics. Identification patterns show only minor differences across demographic characteristics. The main differences were between cancer risk factors, with greatest identification of smoking, UV exposure and passive smoking as 'large' or 'moderate' risks, and least identification of not eating enough fruit and vegetables (Fig. 8).

Figures 9, 10, 11, 12, 13, 14, 15, 16 show the percentage of respondents with 'protective' behaviours across the seven factors associated with cancer risk, by respondent demographic characteristics. Similar to the pattern seen with cancer risk factors, differences were greatest between behaviours than across demographic characteristics. Respondents were most likely to report sun protective behaviour (Fig. 9) and to be a nonsmoker (Fig. 10), and least likely to consume the recommended daily intake of five or more vegetable serves (Fig. 14).

The relationship between respondent characteristics (sex, age, location, education and country of birth) and odds of identifying each cancer risk factor as 'Moderate/ large' as opposed to 'None/slight' are shown in Table 2, with a logistic-regression model for each of the seven risk factors. Odds ratios are shown in the first column of each model, and $p$-values in the second column, with $p$ values of less than 0.05 considered to be significant. Significant values are shaded.
Controlling for other factors, women were more likely than men to identify UV exposure, smoking, passive smoking, and drinking alcohol as moderate/large cancer risk factors. In comparison to respondents aged 1829 years, those aged 50 years and over were more likely to identify five of the seven items as moderate/large risk factors. Those aged 30-49 years were less likely than those aged 18-29 years to identify being overweight as a moderate or large risk factor, but more likely to identify not eating enough vegetables and not eating enough fruit. Those living in regional areas of NSW were less likely than those resident in metropolitan area (Sydney) to identify being overweight as a moderate/large cancer risk factor. Those with post-school education were more likely than those with a Year 10 education or less to identify smoking as a moderate/large cancer risk factor, while those educated to Year 11 or 12 were less likely to identify being overweight. No significant results were found by country of birth.

Table 3 displays logistic regressions with respondent characteristics (sex, age, location, education and country of birth) as independent variables, and one of seven 'protective' behaviours-in relation to cancer risk factors-forming the dependent variable in each of the seven models. Female respondents were more likely than their male counterparts to practise all the 'protective' behaviours, except for being 'sunsafe'. Respondents aged 30-49 years were more likely than those under 30 years 


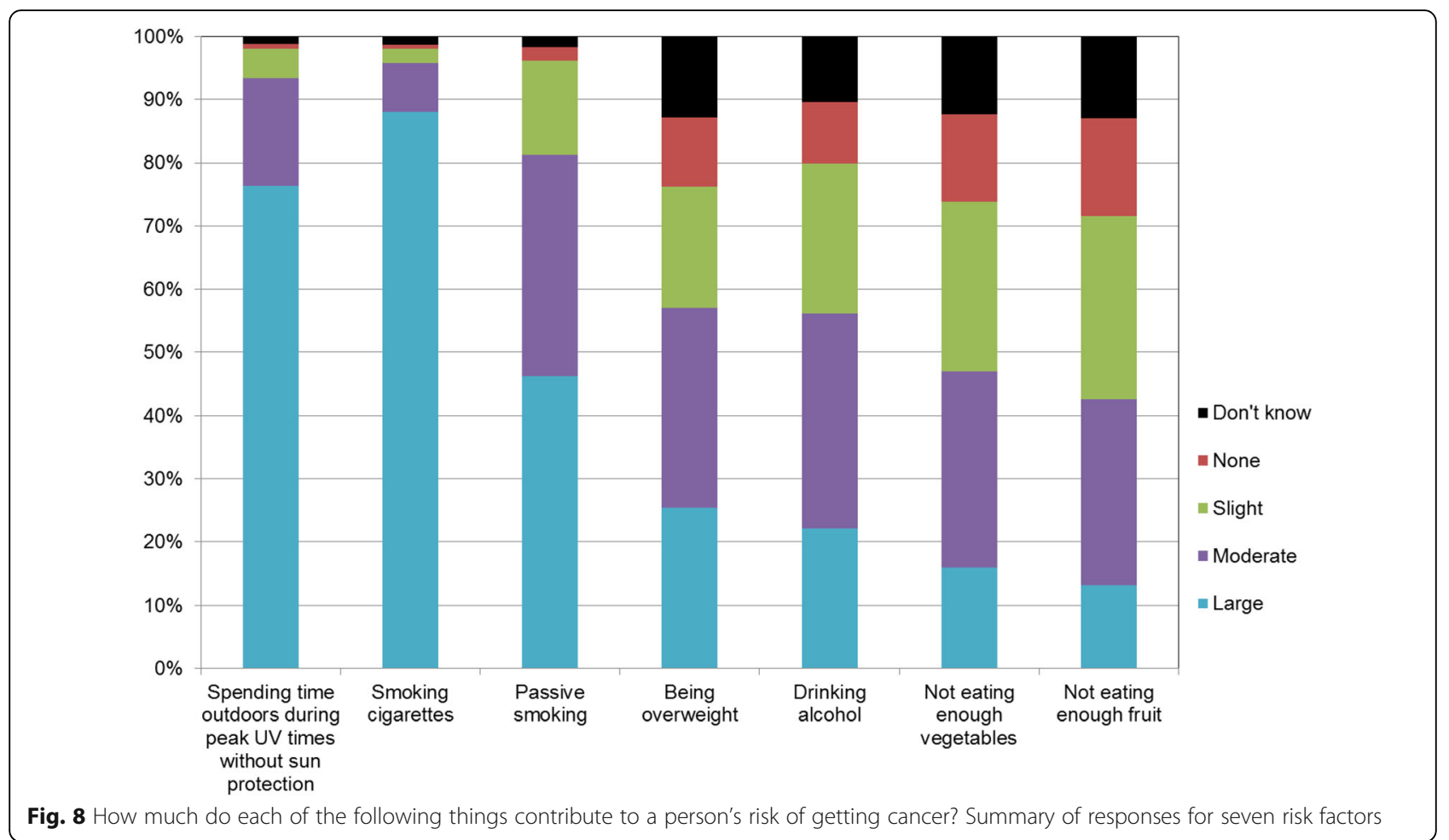

to practise sunsafe behaviour, but less likely to be within the healthy weight range. Respondents aged 50 years and over were more likely than those aged 18-29 years to practise sunsafe behaviour, to be non-smokers and to avoid passive smoke, to have lower-risk alcohol intake and to eat two or more fruit serves daily. However they were also more likely to be overweight.

Those living in regional areas of New South Wales were more likely to practise sunsafe behaviour and to eat five or more daily vegetable servings, but less likely

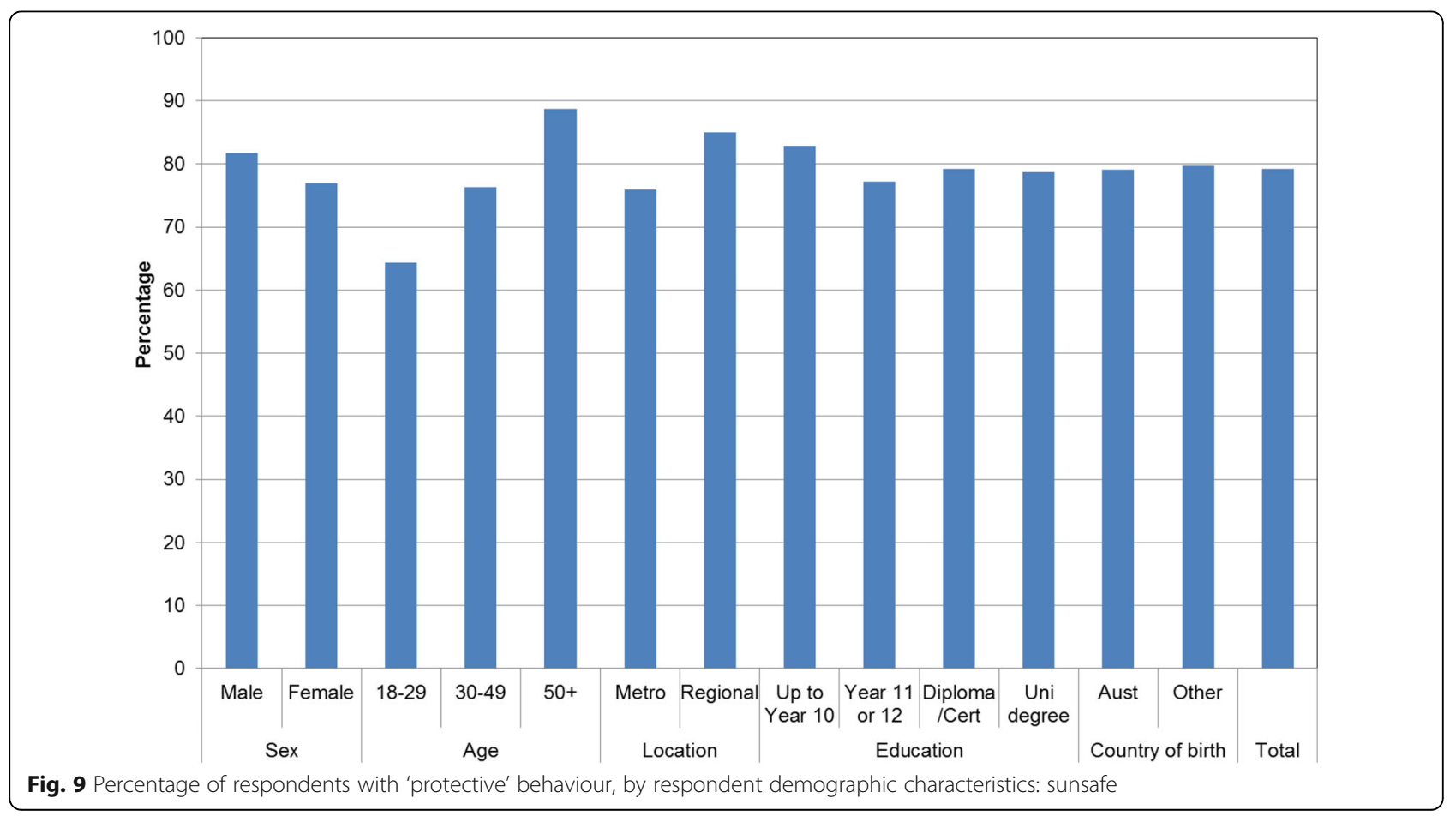




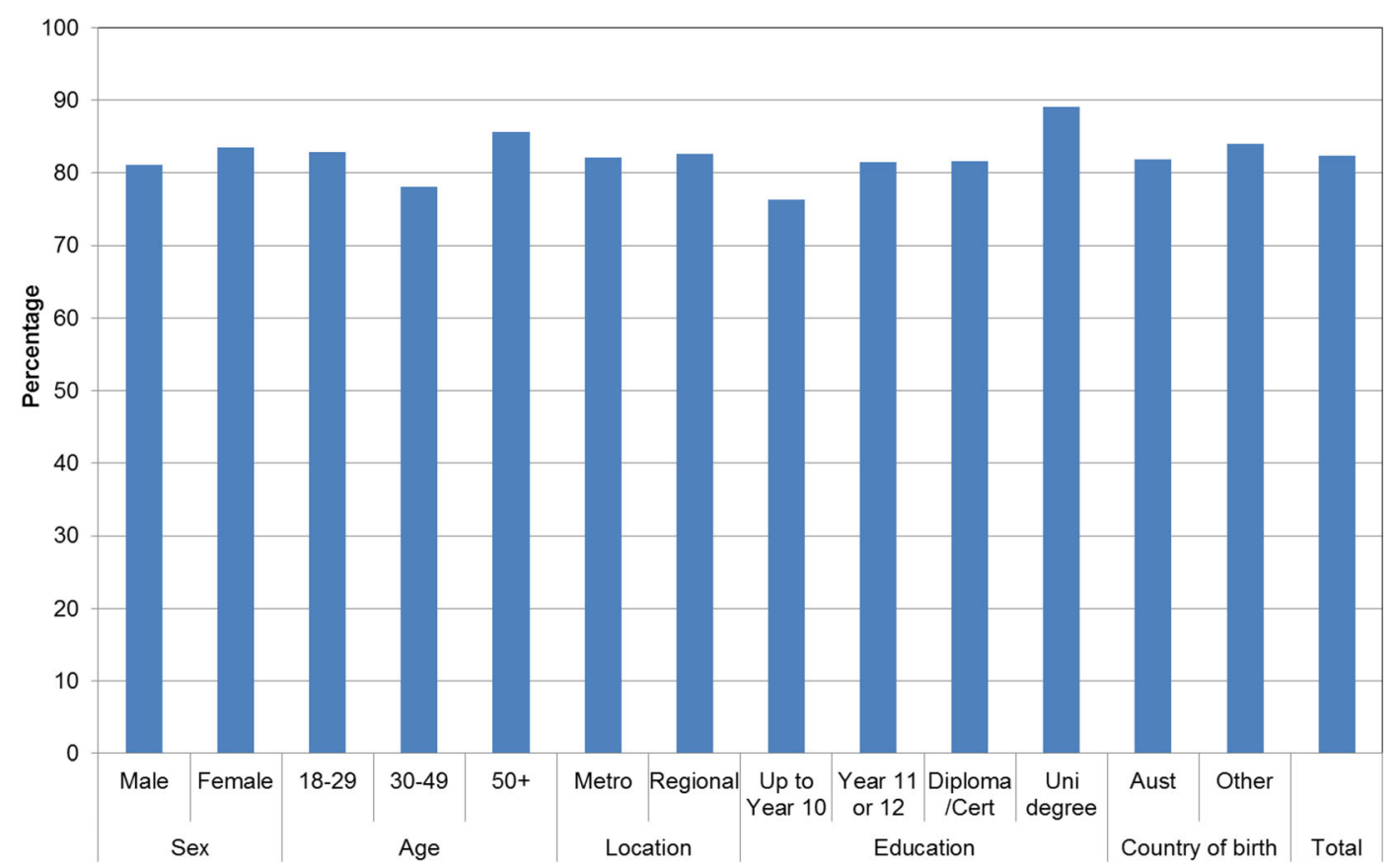

Fig. 10 Percentage of respondents with 'protective' behaviour, by respondent demographic characteristics: non-smoker

to be within the healthy weight range. Respondents with post-Year 10 education were more likely to be nonsmokers and to avoid passive smoke, those with Year 11 or 12 or a university degree were more likely to be within the healthy weight range, and those with a university degree were more likely to consume two or more servings of fruit daily. Respondents born outside Australia were more likely to be within the healthy weight range and to eat two or more daily fruit serves.

Table 4 shows relationships between identification of cancer risk factors as moderate/large and associated behaviours, controlling for respondent demographic

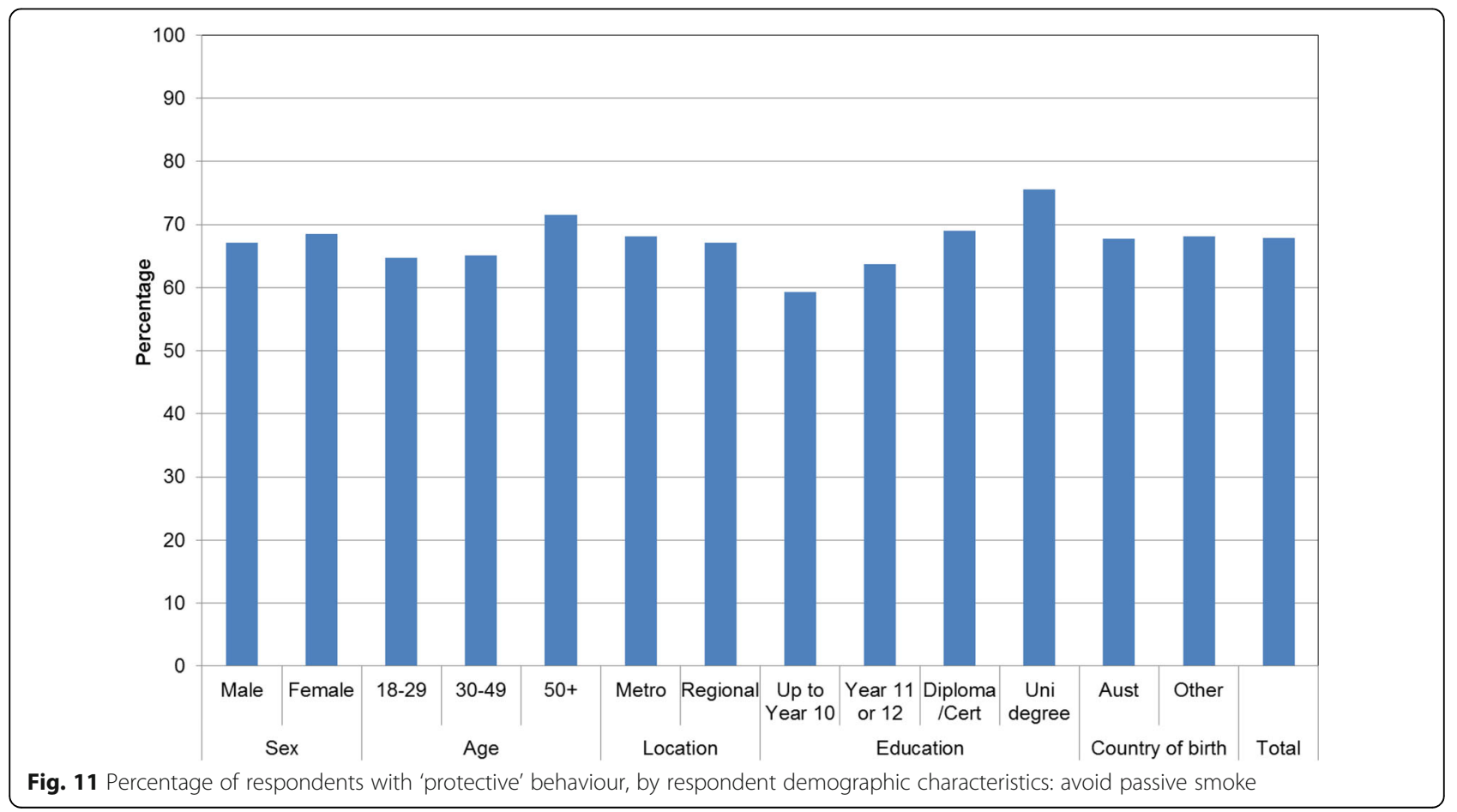




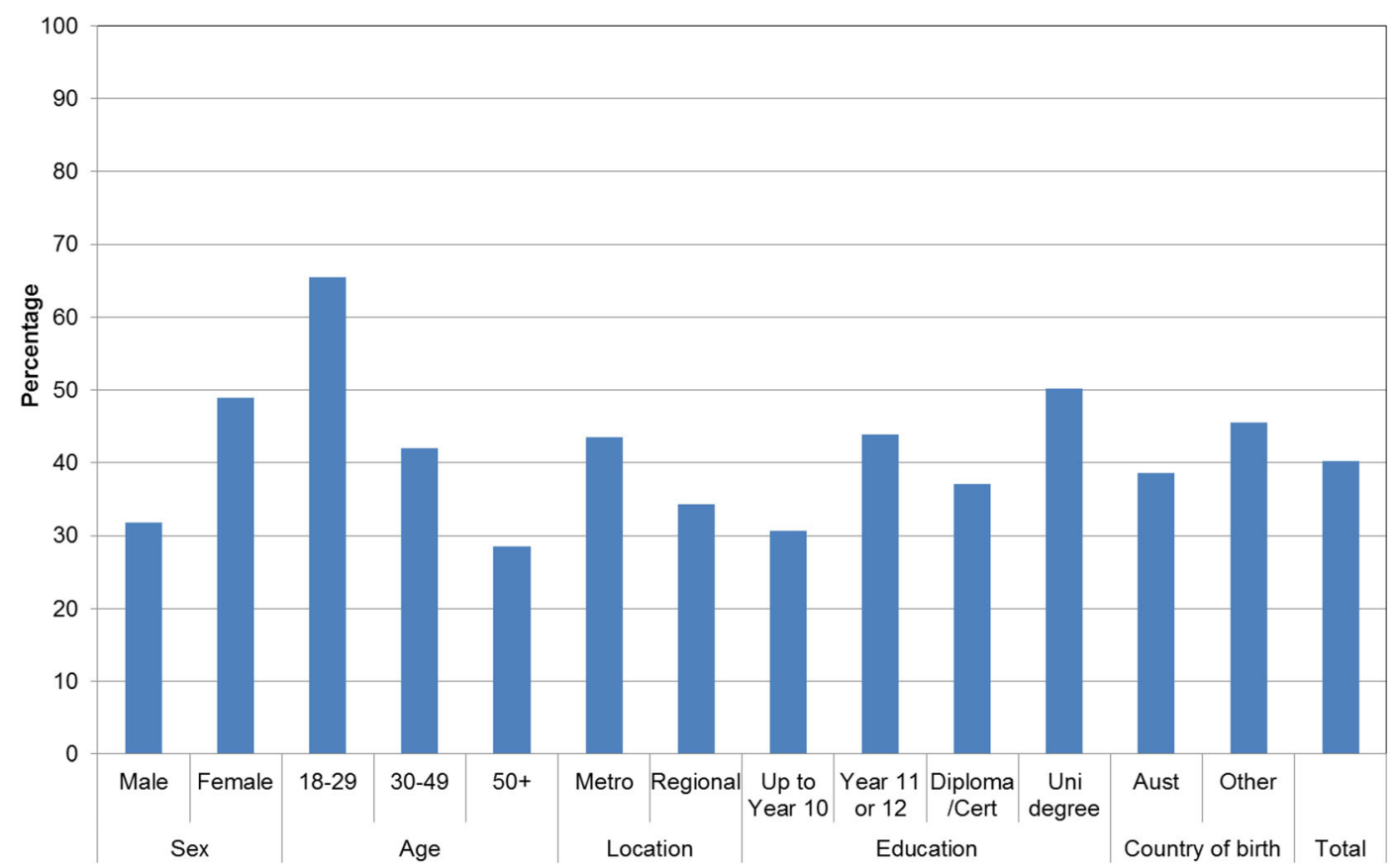

Fig. 12 Percentage of respondents with 'protective' behaviour, by respondent demographic characteristics: healthy weight

characteristics. While women, older respondents and more educated respondents were more likely to report 'protective' behaviours related to cancer risk factors, the most important correlate of 'protective' behaviour across the seven items was found to be identification of the associated risk factor as moderate/large. Those who identify UV exposure as a 'moderate' or 'large' risk factor were more likely to report they did not try to get a tan nor did they use a solarium over summer ('Sunsafe') (Model 15). Identification of cigarette smoking as a moderate/ large risk factor is correlated with being a non-smoker (Model 16). Those who report passive smoking as a

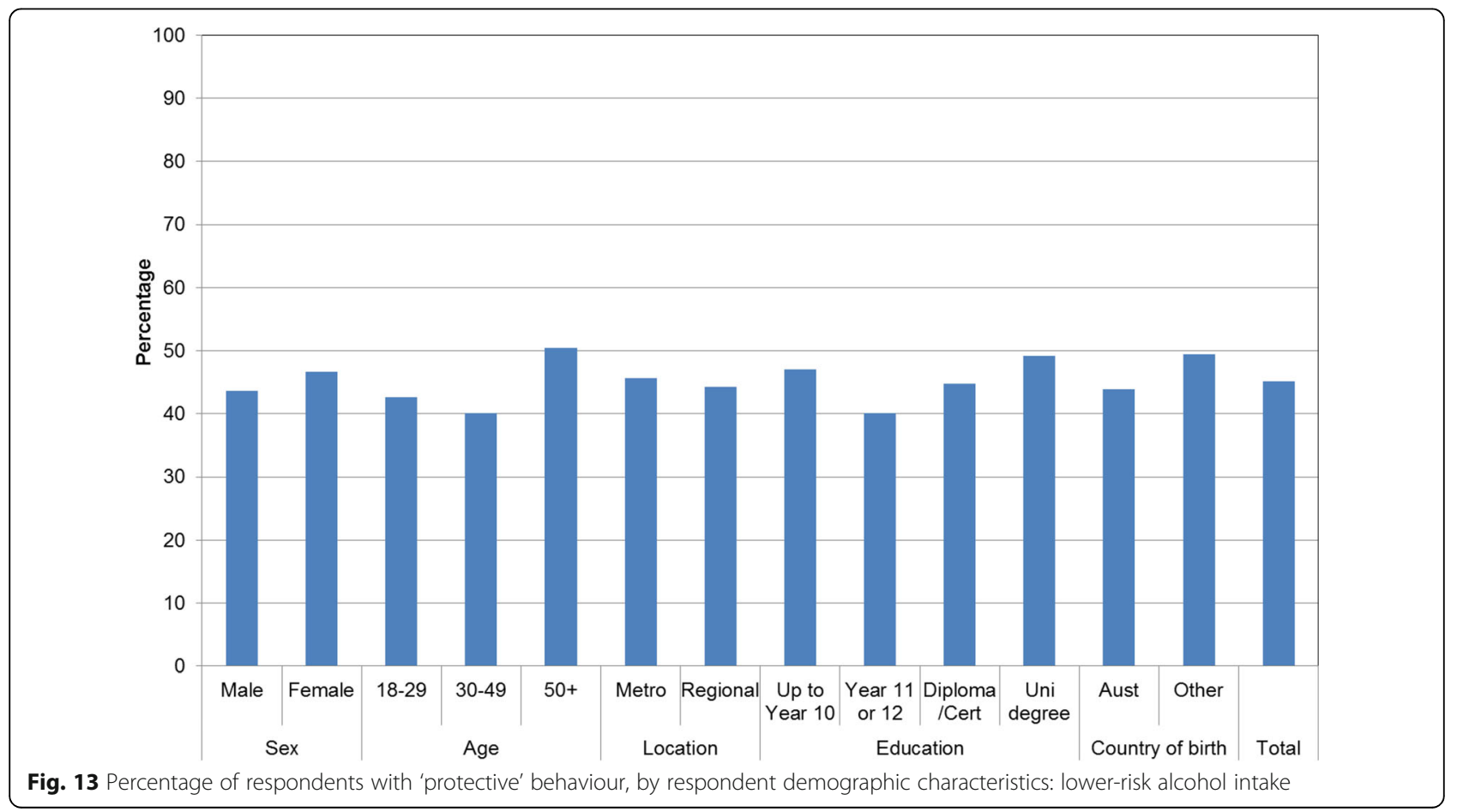




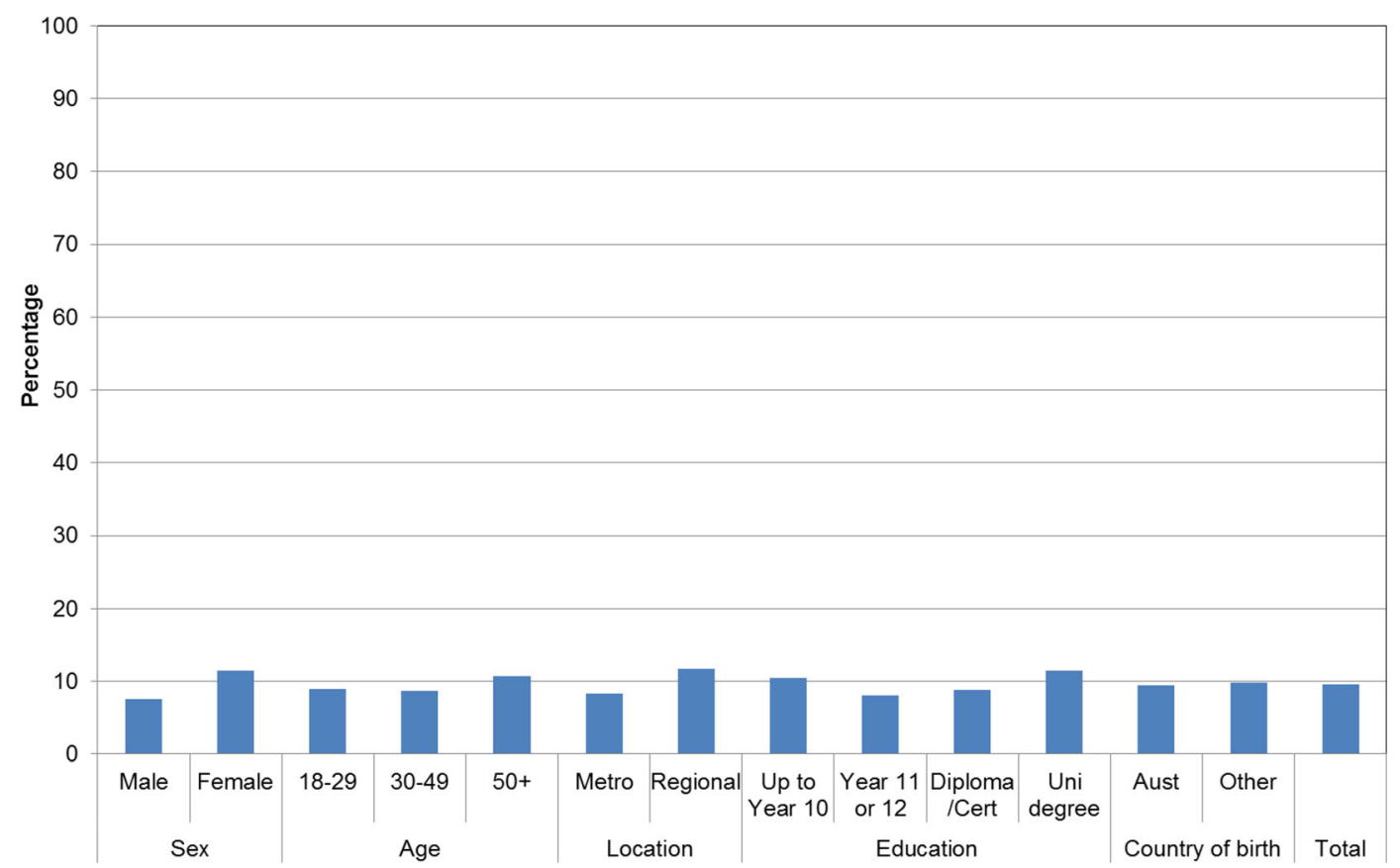

Fig. 14 Percentage of respondents with 'protective' behaviour, by respondent demographic characteristics: five or more vegetable serves daily

'moderate' or 'large' cancer risk factor were more likely to avoid exposure to others' cigarette smoke (Model 17) even when controlling for smoker status (Model 18). Identification of alcohol as a moderate/large risk factor was associated with lower-risk drinking patterns (Model 20). Identification of not eating enough fruit as a moderate/ large risk factor was associated with a higher probability of eating two or more serves of fruit daily (Model 22).

Risk-factor identification as moderate/large was the greatest correlate for three of the seven 'protective' behaviours ('Non-smoker', 'Avoid passive smoke', and 'Lower-risk alcohol intake') and was significant for

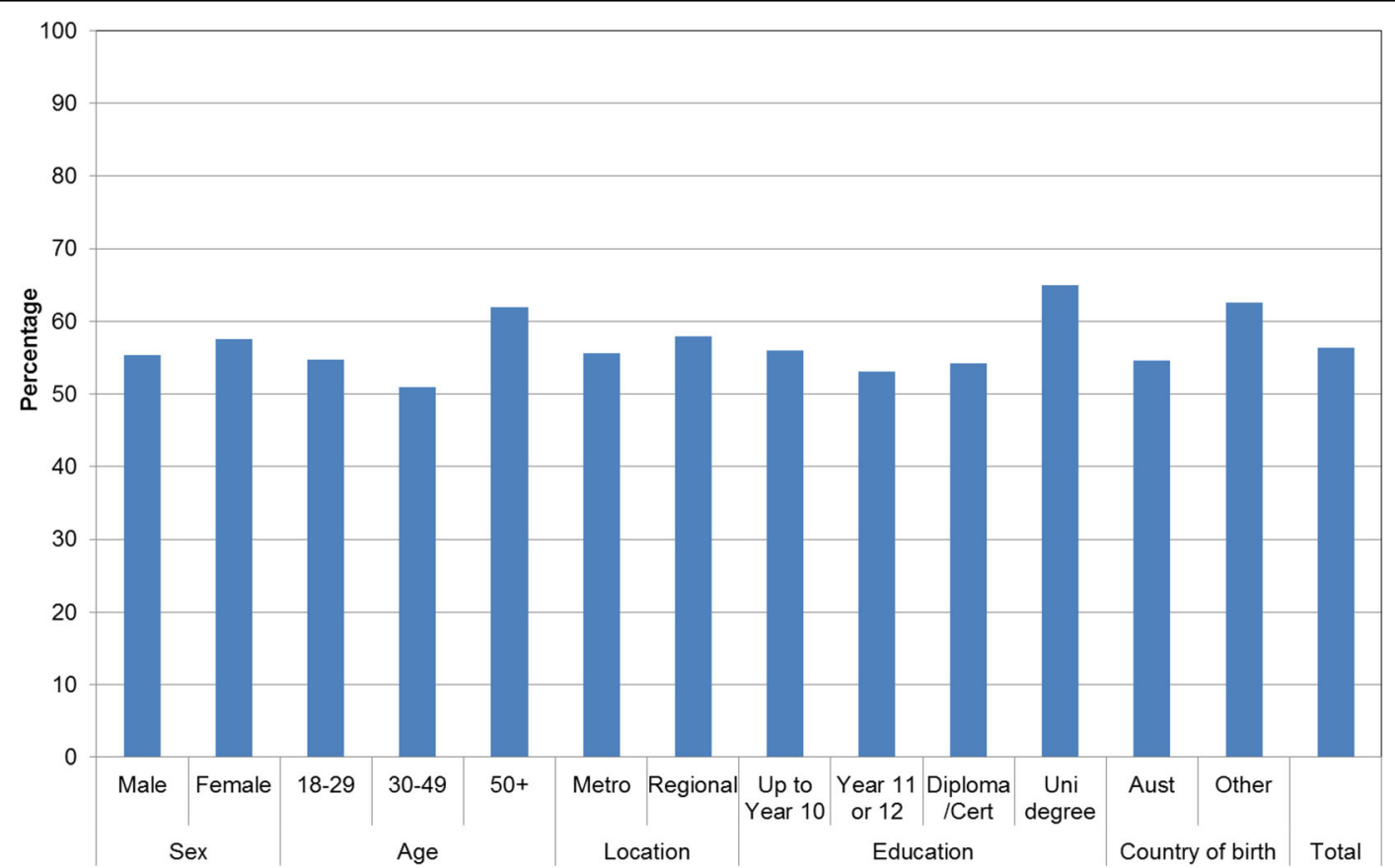

Fig. 15 Percentage of respondents with 'protective' behaviour, by respondent demographic characteristics: two or more fruit serves daily 


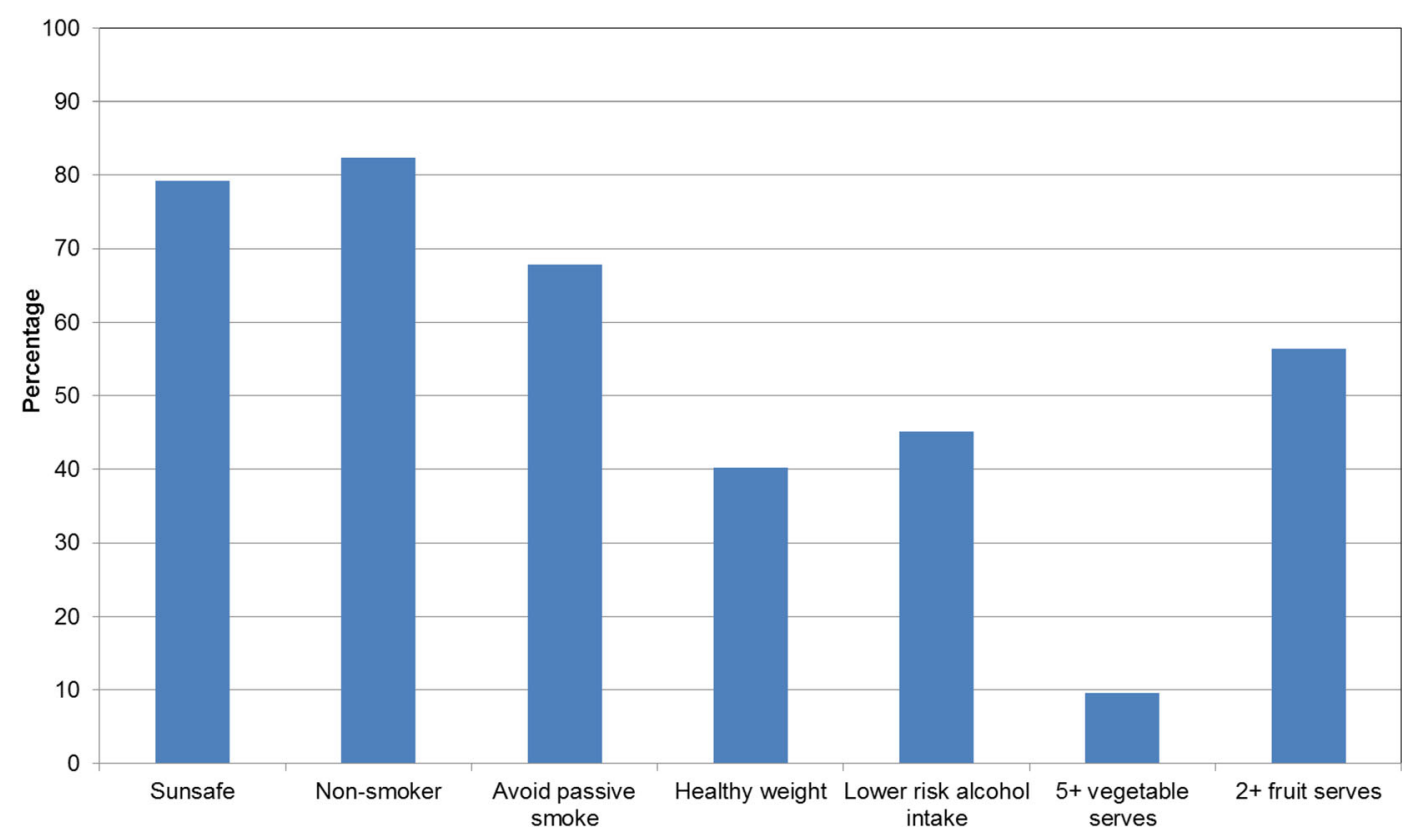

Fig. 16 Percentage of respondents with 'protective' behaviour, by respondent demographic characteristics: summary of seven 'protective' behaviours

two others ('Sunsafe' and ' $2+$ fruit serves). It was not a significant correlate for 'Healthy weight' nor '5+ vegetable serves'.

We ran other logistic-regression models to test whether identification of a cancer risk factor remained correlated with its associated 'protective' behaviour even when controlling for identification of other risk factors. We found that only identification of UV exposure was associated with sun protective behaviour; identification of none of the other six cancer risk factors was associated with sun protective behaviour. Similarly, only identification of drinking alcohol as a

Table 2 Logistic regressions

\begin{tabular}{|c|c|c|c|c|c|c|c|c|c|c|c|c|c|c|}
\hline \multirow[b]{3}{*}{ Characteristic } & \multicolumn{2}{|c|}{ Model 1} & \multicolumn{2}{|c|}{ Model 2} & \multicolumn{2}{|c|}{ Model 3} & \multicolumn{2}{|c|}{ Model 4} & \multicolumn{2}{|c|}{ Model 5} & \multicolumn{2}{|c|}{ Model 6} & \multicolumn{2}{|c|}{ Model 7} \\
\hline & \multicolumn{2}{|c|}{$\begin{array}{l}\text { Spending time outdoors } \\
\text { during peak UV times } \\
\text { without sun protection }\end{array}$} & \multicolumn{2}{|c|}{$\begin{array}{l}\text { Smoking } \\
\text { cigarettes }\end{array}$} & \multicolumn{2}{|c|}{$\begin{array}{l}\text { Passive } \\
\text { smoking }\end{array}$} & \multicolumn{2}{|c|}{$\begin{array}{c}\text { Being } \\
\text { overweight }\end{array}$} & \multicolumn{2}{|c|}{$\begin{array}{l}\text { Drinking } \\
\text { alcohol }\end{array}$} & \multicolumn{2}{|c|}{$\begin{array}{l}\text { Not eating } \\
\text { enough } \\
\text { vegetables }\end{array}$} & \multicolumn{2}{|c|}{$\begin{array}{l}\text { Not eating } \\
\text { enough fruit }\end{array}$} \\
\hline & OR & $p$ & OR & $p$ & OR & $\mathrm{p}$ & OR & $p$ & OR & $\mathrm{p}$ & OR & $p$ & OR & $p$ \\
\hline Sex & & & & & & & & & & & & & & \\
\hline Ref cat: Male & 1.00 & & 1.00 & & 1.00 & & 1.00 & & 1.00 & & 1.00 & & 1.00 & \\
\hline Female & 1.69 & 0.001 & 2.61 & 0.000 & 1.34 & 0.002 & 1.08 & 0.338 & 1.74 & 0.000 & 1.06 & 0.455 & 1.07 & 0.377 \\
\hline Age & & & & & & & & & & & & & & \\
\hline Ref cat: $18-29$ & 1.00 & & 1.00 & & 1.00 & & 1.00 & & 1.00 & & 1.00 & & 1.00 & \\
\hline $30-49$ & 1.36 & 0.126 & 1.16 & 0.602 & 0.92 & 0.527 & 0.77 & 0.018 & 1.14 & 0.218 & 1.41 & 0.001 & 1.28 & 0.021 \\
\hline $50+$ & 1.77 & 0.007 & 1.82 & 0.047 & 0.96 & 0.776 & 0.96 & 0.739 & 1.31 & 0.013 & 2.26 & 0.000 & 2.02 & 0.000 \\
\hline Location & & & & & & & & & & & & & & \\
\hline Ref cat: Metro & 1.00 & & 1.00 & & 1.00 & & 1.00 & & 1.00 & & 1.00 & & 1.00 & \\
\hline Regional & 1.35 & 0.085 & 0.90 & 0.640 & 0.98 & 0.851 & 0.85 & 0.047 & 0.87 & 0.092 & 0.89 & 0.136 & 0.91 & 0.217 \\
\hline Education & & & & & & & & & & & & & & \\
\hline Ref cat: < Year 10 & 1.00 & & 1.00 & & 1.00 & & 1.00 & & 1.00 & & 1.00 & & 1.00 & \\
\hline Year 11 or 12 & 1.45 & 0.195 & 1.91 & 0.050 & 0.77 & 0.111 & 0.75 & 0.038 & 1.15 & 0.307 & 0.95 & 0.686 & 0.95 & 0.713 \\
\hline Diploma/Cert & 0.99 & 0.974 & 2.05 & 0.009 & 0.78 & 0.081 & 0.82 & 0.107 & 0.92 & 0.468 & 1.03 & 0.815 & 0.94 & 0.597 \\
\hline Uni degree & 1.17 & 0.569 & 2.39 & 0.012 & 0.90 & 0.540 & 0.85 & 0.250 & 1.29 & 0.057 & 1.28 & 0.063 & 1.15 & 0.293 \\
\hline Country of birth & & & & & & & & & & & & & & \\
\hline Ref cat: Australia & 1.00 & & 1.00 & & 1.00 & & 1.00 & & 1.00 & & 1.00 & & 1.00 & \\
\hline Other & 0.78 & 0.167 & 0.72 & 0.170 & 1.01 & 0.958 & 1.06 & 0.570 & 1.19 & 0.070 & 1.11 & 0.250 & 1.04 & 0.707 \\
\hline$n$ & 3,262 & & 3,259 & & 3,244 & & 2,882 & & 2,960 & & 2,907 & & 2,895 & \\
\hline
\end{tabular}

Identification of seven cancer risk factors. How much do each of the following things contribute to a person's risk of getting cancer? Odds ratios of 'Moderate/ large' response vs 'None/Slight' response ('Don't know' excluded) by respondent characteristics

OR Odd ratio, $p$-value, Ref cat Reference category, $n$ sample number. $p$-values of less than 0.05 are shaded 
Table 3 Logistic regressions

\begin{tabular}{|c|c|c|c|c|c|c|c|c|c|c|c|c|c|c|}
\hline \multirow[b]{3}{*}{ Characteristic } & \multicolumn{2}{|c|}{ Model 8} & \multicolumn{2}{|c|}{ Model 9} & \multicolumn{2}{|c|}{ Model 10} & \multicolumn{2}{|c|}{ Model 11} & \multicolumn{2}{|c|}{ Model 12} & \multicolumn{2}{|c|}{ Model 13} & \multicolumn{2}{|c|}{ Model 14} \\
\hline & \multicolumn{2}{|c|}{ Sunsafe } & \multicolumn{2}{|c|}{ Non-smoker } & \multicolumn{2}{|c|}{$\begin{array}{l}\text { Avoid passive } \\
\text { smoke }\end{array}$} & \multicolumn{2}{|c|}{ Healthy weight } & \multicolumn{2}{|c|}{$\begin{array}{c}\text { Lower risk } \\
\text { alcohol intake }\end{array}$} & \multicolumn{2}{|c|}{$\begin{array}{c}5+\text { vegetable } \\
\text { serves }\end{array}$} & \multicolumn{2}{|c|}{$2+$ fruit serves } \\
\hline & OR & $\mathrm{p}$ & OR & $\mathrm{p}$ & OR & $\mathrm{p}$ & OR & $\mathrm{p}$ & OR & $p$ & OR & $p$ & OR & $\mathrm{p}$ \\
\hline $\begin{array}{l}\text { Sex } \\
\text { Ref cat: Male }\end{array}$ & 1.00 & & 1.00 & & 1.00 & & 1.00 & & 1.00 & & 1.00 & & 1.00 & \\
\hline Female & 0.96 & 0.705 & 1.37 & 0.001 & 1.23 & 0.021 & 1.83 & 0.000 & 1.26 & 0.007 & 1.68 & 0.000 & 1.22 & 0.017 \\
\hline $\begin{array}{l}\text { Age } \\
\text { Ref cat: } 18-29\end{array}$ & 1.00 & & 1.00 & & 1.00 & & 1.00 & & 1.00 & & 1.00 & & 1.00 & \\
\hline $30-49$ & 1.91 & 0.000 & 0.85 & 0.203 & 1.13 & 0.313 & 0.42 & 0.000 & 0.92 & 0.482 & 1.06 & 0.786 & 0.91 & 0.418 \\
\hline $50+$ & 4.58 & 0.000 & 1.64 & 0.000 & 1.72 & 0.000 & 0.26 & 0.000 & 1.48 & 0.001 & 1.34 & 0.140 & 1.48 & 0.001 \\
\hline $\begin{array}{l}\text { Location } \\
\text { Ref cat: Metro }\end{array}$ & 1.00 & & 1.00 & & 1.00 & & 1.00 & & 1.00 & & 1.00 & & 1.00 & \\
\hline Regional & 1.56 & 0.000 & 1.05 & 0.617 & 0.94 & 0.474 & 0.83 & 0.038 & 0.91 & 0.305 & 1.48 & 0.007 & 1.10 & 0.279 \\
\hline $\begin{array}{l}\text { Education } \\
\text { Ref cat: }<\text { Year } 10\end{array}$ & 1.00 & & 1.00 & & 1.00 & & 1.00 & & 1.00 & & 1.00 & & 1.00 & \\
\hline Year 11 or 12 & 1.05 & 0.787 & 1.60 & 0.002 & 1.43 & 0.014 & 1.36 & 0.034 & 0.83 & 0.180 & 0.83 & 0.421 & 0.97 & 0.840 \\
\hline Diploma/Cert & 1.07 & 0.685 & 1.60 & 0.000 & 1.75 & 0.000 & 1.18 & 0.197 & 0.98 & 0.882 & 0.91 & 0.647 & 1.01 & 0.953 \\
\hline Uni degree & 1.33 & 0.126 & 3.19 & 0.000 & 2.63 & 0.000 & 1.61 & 0.001 & 1.20 & 0.193 & 1.40 & 0.145 & 1.65 & 0.001 \\
\hline $\begin{array}{l}\text { Country of birth } \\
\text { Ref cat: Australia }\end{array}$ & 1.00 & & 1.00 & & 1.00 & & 1.00 & & 1.00 & & 1.00 & & 1.00 & \\
\hline Other & 0.88 & 0.286 & 1.01 & 0.910 & 0.88 & 0.232 & 1.43 & 0.000 & 1.20 & 0.065 & 1.06 & 0.733 & 1.29 & 0.011 \\
\hline $\mathrm{n}$ & 2,474 & & 3,301 & & 2,473 & & 2,740 & & 2,462 & & 2,474 & & 2,474 & \\
\hline
\end{tabular}

'Protective' behaviours by respondent characteristics

$O R$ Odd ratio, $p p$-value, Ref cat Reference category, $n$ sample number. $p$-values of less than 0.05 are shaded

risk factor was associated with lower-risk alcohol intake. Identification of both smoking cigarettes and passive smoking as risk factors were associated with being a non-smoker and avoiding passive smoking, but not any other identifications. Broadly speaking, this indicates that behaviour and beliefs about risk and are specific to those single domains.
No risk factor identifications were correlated to being a healthy weight nor with consuming five or more vegetable serves daily. In contrast, identification of passive smoking, being overweight, drinking alcohol, not eating enough vegetables, and not eating enough fruit were all significantly associated with eating two or more serves of fruit daily.

Table 4 Logistic regressions

\begin{tabular}{|c|c|c|c|c|c|c|c|c|c|c|c|c|c|c|c|c|}
\hline \multirow[b]{2}{*}{ Characteristic } & \multicolumn{2}{|c|}{ Model 15} & \multicolumn{2}{|c|}{ Model 16} & \multicolumn{2}{|c|}{ Model 17} & \multicolumn{2}{|c|}{ Model 18} & \multicolumn{2}{|c|}{ Model 19} & \multicolumn{2}{|c|}{ Model 20} & \multicolumn{2}{|c|}{ Model 21} & \multicolumn{2}{|c|}{ Model 22} \\
\hline & \multicolumn{2}{|c|}{ Sunsafe } & \multicolumn{2}{|c|}{ Non-smoker } & \multicolumn{2}{|c|}{$\begin{array}{l}\text { Avoid passive } \\
\text { smoke } 1\end{array}$} & \multicolumn{2}{|c|}{$\begin{array}{l}\text { Avoid passive } \\
\text { smoke } 2\end{array}$} & \multicolumn{2}{|c|}{ Healthy weight } & \multicolumn{2}{|c|}{$\begin{array}{l}\text { Lower risk alcohol } \\
\text { intake }\end{array}$} & \multicolumn{2}{|c|}{$\begin{array}{l}5+\text { vegetable } \\
\text { serves }\end{array}$} & \multicolumn{2}{|c|}{$\begin{array}{l}2+\text { fruit } \\
\text { serves }\end{array}$} \\
\hline Ref cat: Male & 1.00 & & 1.00 & & 1.00 & & 1.00 & & 1.00 & & 1.00 & & 1.00 & & 1.00 & \\
\hline Female & 0.94 & 0.561 & 1.28 & 0.011 & 1.17 & 0.089 & 1.12 & 0.306 & 1.82 & 0.000 & 1.23 & 0.022 & 1.72 & 0.000 & 1.15 & 0.133 \\
\hline $\begin{array}{l}\text { Age } \\
\text { Ref cat: } 18-29\end{array}$ & 1.00 & & 1.00 & & 1.00 & & 1.00 & & 1.00 & & 1.00 & & 1.00 & & 1.00 & \\
\hline $\begin{array}{l}30-49 \\
50+\end{array}$ & $\begin{array}{l}1.78 \\
4.18\end{array}$ & $\begin{array}{l}0.000 \\
0.000\end{array}$ & $\begin{array}{l}0.86 \\
1.63\end{array}$ & $\begin{array}{l}0.227 \\
0.000\end{array}$ & $\begin{array}{l}1.17 \\
1.79\end{array}$ & $\begin{array}{l}0.214 \\
0.000\end{array}$ & $\begin{array}{l}1.26 \\
1.58\end{array}$ & $\begin{array}{l}0.105 \\
0.002\end{array}$ & $\begin{array}{l}0.45 \\
0.27\end{array}$ & $\begin{array}{l}0.000 \\
0.000\end{array}$ & $\begin{array}{l}0.89 \\
1.44\end{array}$ & $\begin{array}{l}0.351 \\
0.004\end{array}$ & $\begin{array}{l}1.20 \\
1.56\end{array}$ & $\begin{array}{l}0.412 \\
0.042\end{array}$ & $\begin{array}{l}0.97 \\
1.50\end{array}$ & $\begin{array}{l}0.793 \\
0.001\end{array}$ \\
\hline $\begin{array}{l}\text { Location } \\
\text { Ref cat: Metro } \\
\text { Regional }\end{array}$ & $\begin{array}{l}1.00 \\
1.54\end{array}$ & 0.000 & $\begin{array}{l}1.00 \\
1.06\end{array}$ & 0.580 & $\begin{array}{l}1.00 \\
0.92\end{array}$ & 0.362 & $\begin{array}{l}1.00 \\
0.87\end{array}$ & 0.215 & $\begin{array}{l}1.00 \\
0.83\end{array}$ & 0.053 & $\begin{array}{l}1.00 \\
0.95\end{array}$ & 0.557 & $\begin{array}{l}1.00 \\
1.46\end{array}$ & 0.014 & $\begin{array}{l}1.00 \\
1.20\end{array}$ & 0.054 \\
\hline $\begin{array}{l}\text { Education } \\
\text { Ref cat: }<\text { Year } 10\end{array}$ & 1.00 & & 1.00 & & 1.00 & & 1.00 & & 1.00 & & 1.00 & & 1.00 & & 1.00 & \\
\hline Year 11 or 12 & 1.02 & 0.938 & 1.53 & 0.005 & 1.62 & 0.002 & 1.42 & 0.044 & 1.36 & 0.052 & 0.88 & 0.405 & 0.76 & 0.284 & 0.98 & 0.875 \\
\hline Diploma/Cert & 1.05 & 0.759 & 1.58 & 0.000 & 1.87 & 0.000 & 1.67 & 0.001 & 1.14 & 0.350 & 1.05 & 0.723 & 0.98 & 0.925 & 1.04 & 0.782 \\
\hline Uni degree & 1.37 & 0.103 & 3.14 & 0.000 & 2.86 & 0.000 & 2.09 & 0.000 & 1.58 & 0.003 & 1.27 & 0.107 & 1.39 & 0.180 & 1.74 & 0.000 \\
\hline $\begin{array}{l}\text { Country of birth } \\
\text { Ref cat:Australia }\end{array}$ & 1.00 & & 1.00 & & 1.00 & & 1.00 & & 1.00 & & 1.00 & & 1.00 & & 1.00 & \\
\hline Other & 0.92 & 0.525 & 1.03 & 0.830 & 0.86 & 0.192 & 0.85 & 0.200 & 1.33 & 0.006 & 1.20 & 0.080 & 1.05 & 0.763 & 1.26 & 0.034 \\
\hline How much do ea & $\begin{array}{r}\text { of the } \mathrm{f} \\
\text { Sper } \\
\text { outdoor } \\
\text { UV time } \\
\text { pr }\end{array}$ & $\begin{array}{l}\text { g thing } \\
\text { me } \\
\text { g peak } \\
\text { ut sun } \\
\end{array}$ & contrib & to a pe & on's risk & getting & $\begin{array}{r}\text { Pas } \\
\text { smo }\end{array}$ & & Being o & veight & $\begin{array}{l}\text { Drin } \\
\text { alcc }\end{array}$ & & $\begin{array}{r}\text { Not eatir } \\
\text { vege }\end{array}$ & $\begin{array}{l}\text { nough } \\
\text { les }\end{array}$ & $\begin{array}{r}\text { Not eatin } \\
\mathrm{fr}\end{array}$ & nough \\
\hline $\begin{array}{l}\text { Ref cat: } \\
\text { None/slight } \\
\text { Moderate/large }\end{array}$ & $\begin{array}{l}1.00 \\
2.14\end{array}$ & 0.000 & $\begin{array}{l}1.00 \\
5.16\end{array}$ & 0.000 & $\begin{array}{l}1.00 \\
3.73\end{array}$ & 0.000 & $\begin{array}{l}1.00 \\
3.16\end{array}$ & 0.000 & $\begin{array}{l}1.00 \\
1.06\end{array}$ & 0.556 & $\begin{array}{l}1.00 \\
1.58\end{array}$ & 0.000 & $\begin{array}{l}1.00 \\
1.31\end{array}$ & 0.072 & $\begin{array}{l}1.00 \\
1.68\end{array}$ & 0.000 \\
\hline $\begin{array}{l}\text { Smoking status } \\
\text { Ref cat: Smoker } \\
\text { Non-smoker }\end{array}$ & & & & & & & $\begin{array}{r}1.00 \\
14.70\end{array}$ & 0.000 & & & & & & & & \\
\hline $\mathrm{n}$ & 2,448 & & 3,259 & & 2,429 & & 2,429 & & 2,410 & & 2,206 & & 2,178 & & 2,165 & \\
\hline
\end{tabular}

'Protective' behaviours by respondent characteristics and identification of related cancer risk factors

OR Odd ratio, $p$ p-value, Ref cat Reference category, $n$ sample number. $p$-values of less than 0.05 are shaded 


\section{Discussion}

This is one of the first studies to use multivariate analysis to examine the association between awareness of cancer risk factors and health behaviours across seven lifestylemodifiable areas (sun exposure, smoking, passive smoking, healthy weight, alcohol, vegetable consumption, and fruit consumption). Increasing age was a significant predictor of all cancer protective behaviours and a range of demographic characteristics were associated with awareness and behaviours related to other cancer risk factors. After controlling for demographic factors, except for healthy weight and vegetable consumption, awareness of cancer risk was a significant predictor of the associated cancer protective behaviour.

The lack of correlation for healthy weight may have been because of the complexity of contributors to maintaining a healthy weight, and lack of self-awareness of weight status $[20,21]$. The lack of correlation for ' $5+$ vegetable serves' may have been because so few respondents consumed this number of serves daily-less than 10\%. When Model 21 was rerun with the dependent variable as ' 3 + vegetable serves' (some health bodies recommend 5 serves daily of vegetables and fruit together), identification of 'Not eating enough vegetables' as a cancer risk factor became a significant correlate, with an odds ratio of 1.33 and a $p$-value of 0.001 (not shown).

\section{Awareness is important}

Cancer prevention activities require a range of complementary approaches. There are a plethora of health promotion models and theories that guide many successful public health campaigns, and risk factor awareness is known to be important in influencing attitudes and intentions [22, 23]. Participants in this study reported low levels of awareness of four leading cancer risk factors: being overweight or obese, drinking alcohol, not eating enough vegetables, and not eating enough fruit (Figs. 4, 5, 6, 7). Historically, the largest and most significant cancer prevention campaigns in Australia have focused on UV exposure, and tobacco and related smoke exposure. These have resulted in significant improvements in community knowledge [8, 9]. However, community understanding of other risk factors remains poor [5-8, 24]. Cancer survivors and community population studies consistently report relatively high levels of awareness of the link between cancer and hereditary and environmental risks, but much lower levels of understanding about the role of lifestyle factors [5-7]. Social marketing campaigns are an effective approach in addressing such knowledge gaps and misconceptions about cancer risk factors [11]. Social marketing can change understanding and attitudes, and reframe social norms, but by itself does not change behaviour easily.

\section{Audience segmentation}

Our findings suggest a role for audience segmentation and whole-of-population approaches in social marketing campaigns for cancer prevention. The link between each risk factor and associated behaviour was consistently significant amongst participants aged 50 years or more but this was not the case for other groups. Women, older people and to a lesser extent those with higher education (see Table 2) were most likely to identify UV exposure and cigarette smoking as cancer risk factors. This suggests there is a role for targeted social marketing campaigns, particularly addressing the beliefs of younger people and men about these risk factors. In contrast, community awareness of the cancer risk associated with high body weight, low vegetable/fruit intake and higher risk alcohol consumer was significantly lower than awareness of UV exposure and smoking cigarettes (see Table 2). There is a role for traditional population social marketing campaigns to enhance the awareness of these as cancer risk factors.

\section{Limitations}

Our study had limitations. The survey was only conducted in one Australian state, and out of 30,179 initial email invitations, $10.9 \%$ of invitees completed the survey. While this may imply a bias, previous research has shown that response bias is minimised when considering correlation between variables in multivariate models, [25] as is the case in this study.

Study participants self-reported their behaviours. Thus there is the possibility of social desirability bias; that is, that respondents over-reported the positive behaviours measured. We also do not know what people had in mind when they identified risks as none, slight, moderate or large. We did not measure physical activity risk or behaviours, nor ask about dietary fibre and red and processed meat as other factors associated with cancer risk. Further study including these data would enhance our understanding of the relationship between these factors and healthy weight and nutrition behaviours.

\section{Conclusions}

This study shows that there is high community awareness of UV exposure, smoking, and passive smoking as cancer risk factors. There is lower awareness of the link between cancer and being overweight, alcohol intake, and low fruit and vegetable consumption. Males and younger respondents are less likely to practise the behaviours that help protect against cancer. Since there is a strong correlation between awareness of cancer risk factors and practising the associated protective behaviours, these findings suggest a role for both audience segmentation and whole-of-population approaches in cancer-prevention social marketing campaigns. Targeted campaigns can address 
beliefs of younger people and men about cancer risk factors. Traditional population campaigns can enhance awareness of being overweight, alcohol consumption, and poor vegetable and fruit intake as cancer risk factors.

\section{Additional file}

Additional file 1: 2013 Cancer Prevention Survey instrument. 2013 Cancer Council NSW Cancer Prevention Survey instrument. Extract of survey questions from the 2013 Cancer Prevention Survey instrument. This survey was conducted by Cancer Council New South Wales. (PDF $413 \mathrm{~kb})$

\section{Abbreviations}

AUDIT-C: Alcohol use disorders-identification test-consumption; BMI: Body mass index; NSW: New South Wales; UV: Ultraviolet radiation

\section{Acknowledgements}

We thank Kate Xu for research assistance and two reviewers for their constructive suggestions.

\section{Funding}

This study was funded by Cancer Council NSW. Cancer Council NSW was responsible for designing the survey instrument and commissioning a market research company to conduct the survey and collect the data. Two Cancer Council NSW staff-KC and WW-are co-authors on the manuscript, with their contributions outlined below.

\section{Availability of data and materials}

The data that support the findings of this study are available from Cancer Council NSW but restrictions apply to the availability of these data, which were used under license for the current study, and so are not publicly available. Data are however available from the authors upon reasonable request and with permission of Cancer Council NSW.

\section{Authors' contributions}

KC and WW contributed to the development of the survey instrument and acquisition of data. KC, EJ, RK and BW participated in designing this study. RK was responsible for data analysis. PB, EJ, RK, AS and BW contributed to interpreting data. $\mathrm{PB}, \mathrm{KC}, \mathrm{EJ}, \mathrm{RK}, \mathrm{AS}$ and $\mathrm{BW}$ contributed to drafting the manuscript. PB, KC, EJ, RK, BW and WW contributed to revising the manuscript for important intellectual content. All authors give final approval of the version to be published. Each author has participated sufficiently in the co work to take public responsibility for appropriate portions of the content. All authors agree to be accountable for all aspects of the work in ensuring that questions related to the accuracy or integrity of any part of the work are appropriately investigated and resolved.

\section{Ethics approval and consent to participate}

This study was approved by the Cancer Council NSW Ethics Committee, and Monash University Human Research Ethics Committee (CF14/3853).

Participation in the online survey implied consent.

\section{Consent for publication}

Not applicable.

\section{Competing interests}

The authors declare that they have no competing interests.

\section{Publisher's Note}

Springer Nature remains neutral with regard to jurisdictional claims in published maps and institutional affiliations.

\section{Author details}

'School of Rural Health, Monash University, PO Box 666, Bendigo, VIC 3552, Australia. ${ }^{2} \mathrm{~S} c h o o l$ of Medicine and Public Health, University of Newcastle, University Drive, Callaghan, NSW 2308, Australia. ${ }^{3}$ School of Health and Related Research, University of Sheffield, Regent Court, 30 Regent Street,
Sheffield S1 4DA, UK. ${ }^{4}$ Cancer Council New South Wales, PO Box 572, Kings Cross, Sydney, NSW 1340, Australia.

Received: 19 October 2016 Accepted: 10 August 2017

Published online: 17 August 2017

References

1. Whiteman DC, Webb PM, Green AC, Neale RE, Fritschi L, Bain CJ, et al. Cancers in Australia in 2010 attributable to modifiable factors: summary and conclusions. Aust N Z J Public Health. 2015;39:477-84.

2. Danaei G, Vander Hoorn S, Lopez AD, Murray CJL, Ezzati M, et al. Causes of cancer in the world: comparative risk assessment of nine behavioural and environmental risk factors. Lancet. 2005;366:1784-93.

3. Colditz GA, Wolin KY, Gehlert S. Applying what we know to accelerate cancer prevention. Sci Transl Med. 2012:4:1-9.

4. Prevent Cancer Foundation: Preventable cancers. http://preventcancer.org/ prevention/preventable-cancers/\#sthash.kxK5IcoG.pdf (n.d.). Accessed 18 Oct 2016.

5. Willcox SJ, Stewart BW, Sitas F. What factors do cancer patients believe contribute to the development of their cancer? Cancer Causes Control. 2011;22:1503-11.

6. Thomson AK, Heyworth JS, Girschik J, Slevin T, Saunders C, Fritschi L. Beliefs and perceptions about the causes of breast cancer: a case-control study. BMC Res Notes. 2014;7:558

7. Sanderson SC, Waller J, Jarvis MJ, Humphries SE, Wardle J. Awareness of lifestyle risk factors for cancer and heart disease among adults in the UK. Patient Educ Couns. 2009;74:221-7.

8. Paul C, Tzelepis F, Walsh RA, Girgis A, King L, McKenzie J. Has the investment in public cancer education delivered observable changes in knowledge over the past 10 years? Cancer. 2003;97:2931-9.

9. Cancer Institute NSW. Lifestyle and cancer: knowledge, attitudes and behaviour in NSW 2009. Sydney: Cancer Institute NSW; 2012.

10. Talbot L, Verrinder G. Promoting health: the primary health care approach 3rd ed. Sydney: Elsevier; 2005.

11. Evans WD. How social marketing works in health care. BMJ. 2006;332:1207-10.

12. Borden NH. The concept of the marketing mix. J Advert Res. 1964;4:2-7.

13. Gordon R, McDermott $L$, Stead M, Angus K. The effectiveness of social marketing interventions for health improvement: what's the evidence? Public Health. 2006;120:1133-9.

14. Wakefield MA, Loken B, Hornik RC. Use of mass media campaigns to change health behaviour. Lancet. 2010;376:1261-71.

15. Buykx P, Gilligan C, Ward B, Kippen R, Chapman K. Public support for alcohol policies associated with knowledge of cancer risk. Int J Drug Policy. 2015;26:371-9.

16. National Health and Medical Research Council. Clinical practice guidelines for the management of overweight and obesity in adults, adolescents and children in Australia. Canberra: Commonwealth of Australia; 2013.

17. Bush K, Kivlahan DR, McDonell MB, Fihn SD, Bradley KA. The AUDIT alcohol consumption questions (AUDIT-C): an effective brief screening test for problem drinking. Arch Intern Med. 1998;158:1789-95.

18. Rubinsky AD, Dawson DA, Williams EC, Kivlahan DR, Bradley KA. AUDIT-C scores as a scaled marker of mean daily drinking, alcohol use disorder severity, and probability of alcohol dependence in a U.S. general population sample of drinkers. Alcohol Clin Exp Res. 2013;37:1380-90.

19. National Health and Medical Research Council. Australian dietary guidelines. Canberra: Commonwealth of Australia; 2013.

20. Morley B, Wakefield M, Dunlop S, Hill D. Impact of a mass media campaign linking abdominal obesity and cancer: a natural exposure evaluation. Health Educ Res. 2009;24:1069-79.

21. Vandenbroeck P, Goossens J, Clemens M. Tackling obesities: future choices_obesity system atlas. London: Government Office for Science; 2007.

22. Hill D, Wakefield M. Designing and evaluating population-wide campaigns. In: Stewart BW, Wild CP, editors. World cancer report 201. Geneva: International Agency for Research on Cancer, World Health Organization; 2014.

23. Fabrigar LR, Petty RE, Smith SM, Crites SL Jr. Understanding knowledge effects on attitude-behaviour consistency: the role of relevance, complexity, and amount of knowledge. J Pers Soc Psychol. 2009;90:556-77.

24. MacTiernan A, Fritschi L, Slevin T, Jalleh G, Donovan R, Heyworth J. Public perceptions of cancer risk factors: a Western Australian study. Health Promot J Austr. 2014;25:90-6.

25. Rindfuss RR, Choe MK, Tsuya NO, Bumpass LL, Tamaki E. Do low survey response rates bias results? Evidence from Japan. Demogr Res. 2015;32:26. 